\title{
Saberes tradicionais sobre plantas medicinais e tóxicas: Um estudo de caso na educação de jovens e adultos
}

\author{
Traditional knowledge about medicinal and toxic plants: A case study in youth and adult education \\ Conocimiento tradicional sobre plantas medicinales y tóxicas: Un estudio de caso en educación de \\ jóvenes y adultos
}

Recebido: 28/04/2021 | Revisado: 05/05/2021 | Aceito: 05/05/2021 | Publicado: 21/05/2021

Nilva Soares

ORCID: https://orcid.org/0000-0002-1882-7837 Rede Pública do Estado do Rio Grande do Sul, Brasil E-mail: nilva_soares@hotmail.com

Diego Pascoal Golle

ORCID: https://orcid.org/0000-0002-5264-8007 Universidade de Cruz Alta, Brasil E-mail: dgolle@unicruz.edu.br

Jana Koefender

ORCID: https://orcid.org/0000-0002-5882-9669 Universidade de Cruz Alta, Brasil

E-mail: jkoefender@unicruz.edu.br Juliane Nicolodi Camera

ORCID: https://orcid.org/0000-0001-7182-5788 Universidade de Cruz Alta, Brasil E-mail: jcamera@unicruz.edu.br

André Schoffel

ORCID: https://orcid.org/0000-0002-2501-4834 Universidade de Cruz Alta, Brasil E-mail: andre-schoffel@hotmail.com

\begin{abstract}
Resumo
Os conhecimentos tradicionais sobre o uso de plantas medicinais refletem uma importante prática sociocultural das comunidades, assim como o conhecimento sobre espécies potencialmente tóxicas. Os alunos da Educação de Jovens e Adultos (EJA) caracterizam-se por possuir vivências, saberes e práticas culturais variadas, as quais podem contribuir tanto com o resgate dos saberes tradicionais de comunidades como com a valorização dos conhecimentos prévios dos alunos, característica fundamental dentro dos preceitos da EJA. Assim, o objetivo deste trabalho foi realizar o resgate dos saberes de alunos da Educação de Jovens e Adultos sobre plantas medicinais e tóxicas, comparando-os com os conhecimentos científicos existentes e estimulando a valorização dos saberes oriundos das vivências pessoais. Utilizou-se uma abordagem quali-quantitativa, a partir de um estudo de caso com a totalidade dos estudantes da EJA de uma escola municipal. Foi possível observar que os conhecimentos populares dos educandos estavam em acordo com os conhecimentos científicos. Além de contribuir no resgate destes saberes, os educandos demonstraram entusiasmo em socializar seus conhecimentos e sentiram-se valorizados ao perceber que seus conhecimentos estavam em acordo com as informações científicas.
\end{abstract}

Palavras-chave: Conhecimento popular; Plantas bioativas; Educação em ciências; Ensino.

\begin{abstract}
Traditional knowledge about the use of medicinal plants leads an important socio-cultural practice in communities, as well as knowledge about potentially toxic species. Students of Youth and Adult Education (EJA - in brazilian initials) are characterized by having varied experiences, knowledge and cultural practices, which can contribute both to the recovery of traditional knowledge of communities and to the valorization of students' previous knowledge, a fundamental characteristic within the precepts of EJA. Thus, the objective of this work was to rescue the knowledge of students of Youth and Adult Education about medicinal and toxic plants, comparing them with the existing scientific knowledge and stimulating the valorization of the knowledge from personal experiences. A qualitative and quantitative approach was used, based on a case study with the totality of EJA students from a municipal school. It was possible to observe that the popular knowledge of the students was in agreement with the scientific knowledge. In addition to contributing to the rescue of this knowledge, the students showed enthusiasm for socializing their knowledge and felt valued when realizing that their knowledge was in accordance with scientific information.
\end{abstract}

Keywords: Popular knowledge; Bioactive plants; Science education; Teaching. 


\begin{abstract}
Resumen
El conocimiento tradicional sobre el uso de plantas medicinales refleja una práctica sociocultural importante en las comunidades, así como el conocimiento sobre especies potencialmente tóxicas. Los estudiantes de Educación de Jóvenes y Adultos (EJA) se caracterizan por tener variadas experiencias, conocimientos y prácticas culturales, que pueden contribuir tanto al rescate de los saberes tradicionales de las comunidades como a la valorización de los conocimientos previos de los estudiantes, característica fundamental dentro de los preceptos de EJA. Así, el objetivo de este trabajo fue rescatar los conocimientos de los estudiantes de Educación de Jóvenes y Adultos sobre plantas medicinales y tóxicas, comparándolas con el conocimiento científico existente y estimulando la valorización de conocimientos derivados de experiencias personales. Se utilizó un enfoque cualitativo y cuantitativo, basado en un estudio de caso con todos los estudiantes de EJA de una escuela municipal. Se pudo observar que el conocimiento popular de los estudiantes estaba de acuerdo con el conocimiento científico. Además de contribuir al rescate de este conocimiento, los estudiantes mostraron entusiasmo por socializar sus conocimientos y se sintieron valorados al darse cuenta de que sus conocimientos estaban de acuerdo con la información científica.
\end{abstract}

Palabras clave: Conocimiento popular; Plantas bioactivas; Educación científica; Ensenãnza.

\title{
1. Introdução
}

Evidências históricas demonstram que o uso de plantas com potencial medicinal para amenizar as enfermidades das populações é um costume muito antigo e difundido nas comunidades (Kruprek \& Nedopetalski, 2020). Ainda hoje, em muitas comunidades, o uso das plantas é o principal recurso disponível e, mesmo nas comunidades com acesso aos medicamentos alopáticos, a escolha por plantas medicinais permanece significativa. Conforme Brasil (2006), a Organização Mundial de Saúde (OMS) estima que 80\% das pessoas dos países em desenvolvimento dependam da medicina tradicional para as suas necessidades básicas de saúde e, neste sentido, cerca de $85 \%$ da medicina tradicional envolve o uso de plantas ou extratos destas.

No Brasil, no ano de 2006, foi instituída a Política Nacional de Práticas Integrativas e Complementares no Sistema Único de Saúde (SUS), publicada por meio de Portaria no 971, de 03 de maio de 2006, do Ministério da Saúde (Brasil, 2006). A portaria evidencia a inclusão das plantas medicinais (além de outras terapias integrativas) como opção terapêutica no sistema público de saúde. Conforme Cavaglier e Messeder (2014), outro marco referente ao uso de plantas medicinais no Brasil foi a Política Nacional de Plantas Medicinais e Fitoterápicos (decreto presidencial no 5.813 de 22 de junho de 2006), que objetiva, entre outros aspectos, garantir à população o acesso seguro e o uso racional e sustentável de espécies vegetais.

Também nesse aspecto, é fundamental mencionar a importância da valorização dos conhecimentos populares, principalmente no que se refere aos recursos da flora. Cavaglier e Messeder (2014) asseveram que os saberes populares não deveriam ser subestimados, antes disso, merecem ser valorizados, pois foram o ponto de partida para a descoberta de muitas substâncias que, posteriormente, tornaram-se fármacos comercializados. É necessário um equilíbrio entre os conhecimentos desenvolvidos cientificamente e a valorização dos conhecimentos tradicionais.

Essa relação ou inversão de valores é preocupante, no sentido da supervalorização de um saber em detrimento do outro, o que torna relevante um investimento no resgate aos conhecimentos construídos historicamente pelos povos e comunidades tradicionais [...] (Moreno \& Silva, 2017, p.147).

Os saberes sobre plantas medicinais revelam, ainda, uma importante prática sociocultural das comunidades populações em todo o território nacional (Tomazzoni et al., 2006; Krupek \& Nedopetalski, 2020). Neste sentido, é importante destacar que no Brasil:

[...] o conhecimento tradicional sobre plantas medicinais tem origem na herança gerada por diversas etnias (indígena, negra e europeia) e gradativamente vem contribuindo para o estabelecimento da medicina tradicional brasileira MTB. Esta construção cultural aliada a uma megabiodiversidade possibilita ao país ser um celeiro de conhecimentos sobre o uso sustentável e a conservação das espécies vegetais (Fernandes et al., 2018, p.127). 
Entretanto, assim como o conhecimento sobre plantas com propriedades benéficas à saúde é importante, da mesma forma, é fundamental o conhecimento sobre plantas que possam apresentar toxidez aos seres humanos. Dados do Sistema Nacional de Informações Tóxico-Farmacológicas SINITOX (2020), referente às intoxicações por plantas no ano de 2017 atualizados em 2020, não havendo dados posteriores, revelam que houve 821 intoxicações ocasionadas pelas diferentes formas de utilização das plantas. Por esta razão a discussão para a valorização dos saberes e (re)elaboração de conceitos é importante e o ambiente educacional constitui-se em um espaço legítimo para ampliar este debate. Conforme mencionam Dávila et al. (2016, p.360, grifo nosso):

Não somente as plantas tóxicas podem causar problemas de saúde, como também as plantas medicinais se não forem utilizadas corretamente. Dentro deste contexto, as escolas poderiam auxiliar a comunidade com a abordagem destas plantas em sala de aula para auxiliar no maior conhecimento destes vegetais e evitar casos de intoxicação.

Assim, compreender os conhecimentos sobre as formas adequadas de se relacionar com a biodiversidade vegetal é fundamental. Oler et al. (2019) mencionam que discutir com a população sobre as plantas pode ser uma das melhores estratégias para a redução de casos com acidentes envolvendo espécies tóxicas.

Entretanto, cientistas têm demonstrado preocupação com a constante perda dos saberes tradicionais sobre a flora, especialmente pela falta de diálogo, valorização, mas, também, porque as comunidades mais jovens não demonstram tanto interesse pelos conhecimentos que eram valorizados por seus ancestrais (Santos \& Carvalho, 2018). Dessa forma, valorizar conhecimentos tradicionais e estimular o diálogo sobre plantas medicinais e tóxicas constitui-se em uma estratégia para a continuidade dos saberes e práticas socioculturais das comunidades. Conforme Santos (2010), existe uma ecologia de saberes, na qual todos os sujeitos possuem conhecimentos e, estes conhecimentos, podem ser pluralizados pelo diálogo e pelas práticas coletivas. Ainda neste aspecto, Santos (2004) menciona que a ecologia de saberes busca uma nova forma de relacionamento entre o conhecimento científico e outras formas de conhecimento. No espaço da Educação de Jovens e Adultos (EJA), por exemplo, é possível encontrar um ambiente fértil para o estabelecimento de discussões que tenham como ponto de partida os conhecimentos prévios dos educandos.

A EJA é voltada aos sujeitos que não tiveram acesso, por algum motivo, ao ensino regular na idade apropriada. Esta realidade do não acesso à educação ainda é bastante presente no país (Mello, 2019). Para Oliveira (2014, grifo nosso), os alunos atendidos por essa modalidade de ensino apresentam três especificidades: a etária, a sociocultural e a ético-política. A etária caracteriza-pela variação presente nas classes da EJA, com a presença de jovens, adultos e idosos. A especificidade sociocultural caracteriza os alunos da EJA, na medida em que as atividades educativas são predominantemente voltadas à uma determinada classe social e cultural, ou seja, jovens, adultos e idosos de uma classe economicamente baixa, a qual costuma ser composta por trabalhadores assalariados, do mercado informal ou do campo. Já a especificidade ético-política está na medida em que a EJA está no centro das relações de poder existente entre os escolarizados e os não-escolarizados.

Uma questão fundamental na EJA é valorizar os saberes prévios dos sujeitos, os quais são possuidores de diferentes culturas e vivências. Ademais, conforme Gadotti (2007), este aluno tem a necessidade de ver a aplicação imediata do que está aprendendo e, ao mesmo tempo, precisa estímulo à autoestima. É fundamental compreender que estes conhecimentos emergem da cultura dos sujeitos, compreendendo cultura como o conjunto de saberes, fazeres, regras, normas, crenças, valores e mitos, que podem ser transmitidos à cada geração em um processo de reprodução sociocultural, constituindo-se em um aspecto fundamental para o controle da existência em sociedade e da manutenção da complexidade psicológica e social (MORIN, 2013). Também cabe mencionar que: 
Considerando a pluralidade que caracteriza os sujeitos da EJA, propostas pedagógicas e curriculares precisam ser pensadas no quadro de concepções voltadas à formação humana que contemplem suas subjetividades, seus processos de formação histórico-sociais, no sentido de atender e se adequar às necessidades desse público. É mister repensar formatos, metodologias e práticas, além de garantir uma formação adequada e continuada aos profissionais que nela atuam (Rocha \& Vieira, 2020, p.35).

Frente à contextualização exposta, o presente estudo teve o objetivo de realizar o resgate dos saberes de alunos da Educação de Jovens e Adultos sobre plantas medicinais e tóxicas, comparando-os com os conhecimentos científicos existentes e estimulando a valorização dos conhecimentos prévios existentes.

\section{Metodologia}

Esta pesquisa foi conduzida em uma abordagem quali-quantiativa. De acordo com Minayo (2007), os aspectos quantitativos caracterizam pela mensuração de dados, enquanto a perspectiva qualitativa da pesquisa volta-se à análise dos aspectos da realidade que não são passíveis de quantificação. Assim, a pesquisa quali-quantitativa busca unir estes dois caminhos, desde a coleta até o tratamento das informações, mais voltados à estatística, no âmbito quantitativo e, no âmbito qualitativo, aos aspectos da subjetividade e complexidade (Diehl, 2004, Knechtel, 2014). No que se refere aos procedimentos, esta pesquisa caracterizou-se como um Estudo de Caso que, conforme menciona Gil (2010), consiste na coleta e análise de informações voltadas para o estudo de alguma pessoa, coletivo, situação ou comunidade.

A pesquisa foi realizada com os alunos da educação de jovens e adultos (EJA) de uma escola municipal do município de Cruz Alta, região Noroeste do Estado do Rio Grande do Sul. No total, participaram 25 (vinte e cinco) alunos com idade e gêneros distintos, compreendendo a totalidade dos estudantes desta modalidade de ensino no estabelecimento educacional. Cabe mencionar que a modalidade de EJA é ofertada - na escola em que o estudo ocorreu - apenas durante o turno da noite.

Como instrumento de pesquisa, foi utilizado um questionário semiestruturado, o qual foi acessado pelos participantes para inserir de forma escrita as respostas. Com o intuito de avaliar os conhecimentos empíricos em relação aos científicos, na composição do questionário foram definidas algumas plantas medicinais e tóxicas (sem distinção destas características no questionário). Porém, estas plantas foram definidas a partir de diálogos prévios realizados com os estudantes sobre plantas utilizadas pela população das mais variadas formas (alimentos, plantas medicinais, ornamentais, etc.) o que ocorreu em formato de brainstorming.

Durante a aplicação do questionário, foi entregue aos participantes um Termo de Consentimento Livre e Esclarecido (TCLE), com informações sobre a pesquisa, seus riscos e benefícios; também foi entregue um Termo de Confidencialidade (TC), no qual os autores comprometeram-se a não divulgar nenhum dado pessoal dos participantes. Não obstante, todos os educandos foram informados que poderiam contribuir apenas se estivessem confortáveis com a pesquisa e que poderiam, a qualquer momento, cancelar suas participações. O projeto - contendo o instrumento de pesquisa - foi previamente submetido à apreciação do Comitê de Ética em Pesquisa (CEP) institucional, recebendo o Certificado de Apresentação para Apreciação Ética (CAAE) número 38508214.1.0000.5322. A aprovação pelo CEP ocorreu com a emissão do Parecer Consubstanciado 877.938. Os dados quantitativos foram avaliados por meio de estatística descritiva, com a elaboração de figuras e tabelas. As informações quanlitativas foram interpretadas à luz da análise de Conteúdo de Bardin (2009).

\section{Resultados e Discussão}

Todos os alunos (25 alunos) demonstraram interesse em participar da pesquisa. Não foram consideradas distinções entre os gêneros dos alunos nas análises. A avaliação de faixas etárias, permitiu observar que a maior parte dos participantes se encontrava na faixa de 17 a 20 anos, seguidos por aqueles que estavam na faixa de 21 a 30 anos e, por fim, por aqueles com 
mais de 70 anos (Figura 1). A maioria dos participantes foi composta por pessoas naturais do município em estudo (Figura 1), mas também existiam estudantes de outros municípios do Estado e de outros Estados (todos, atualmente, residentes em Cruz Alta, RS).

Figura 1 - Faixas etárias (a) dos participantes da pesquisa e origem (b) antes de ingressarem na Educação de Jovens e Adultos.

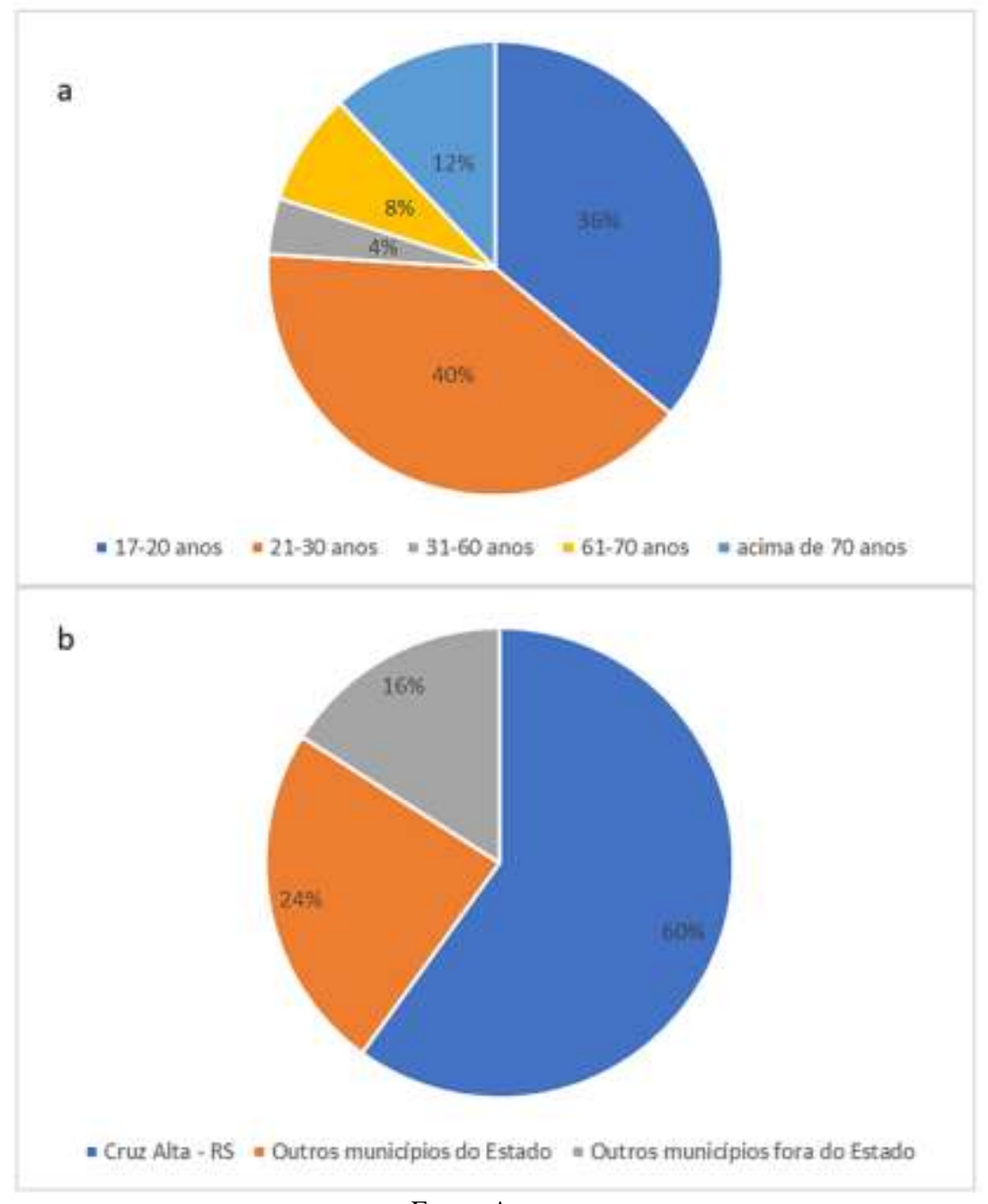

Fonte: Autores.

Os estudantes de EJA trazem consigo uma visão de mundo influenciada por seus traços culturais de origem e por sua vivência social, familiar e profissional. Assim, a visão de mundo que possuem está estreitamente relacionada ao ver e ao fazer. Abertos à aprendizagem, apresentam um olhar que transita entre o receptivo (sensível ao que está sendo trabalhado) e o olhar ativo, caracterizado pelo aspecto explorador, curioso, investigativo (Brasil, 2006).

A maior parte dos estudantes que conciliam os estudos na EJA com o trabalho atuam em atividades similares, a saber: diaristas, mecânicos, serviços gerais e aposentados. Houve estudantes que optaram por não revelar suas profissões. Também houve parte do grupo de estudantes que se caracterizou por não estar atuando no mercado de trabalho, alguns por estarem desempregados e em busca de emprego, outros, em geral estudantes mais jovens, que se dedicavam, no momento, apenas aos estudos.

Uma característica da EJA é a presença de alunos trabalhadores. De acordo com o artigo 37, § $2^{\circ}$ da Lei de Diretrizes e Bases da Educação Nacional (1996) “O poder público viabilizará e estimulará o acesso e permanência do trabalhador na 
escola, mediante ações integradas e complementares". Essas ações estão relacionadas aos cursos e exames que habilitarão os alunos para a continuidade dos estudos na educação regular após sua passagem pela Educação de Jovens e Adultos, além de considerar as características sociais deles, tais como: serem alunos de baixa renda, trabalharem durante o dia, entre outros aspectos.

Apresentando de forma separada, as plantas medicinais e as plantas tóxicas, observa-se que, no que se refere às espécies medicinais, há uma estreita relação entre as indicações mencionadas pelos estudantes e as indicações presentes na literatura. Contudo, de forma geral, as indicações da literatura mostram-se mais amplas. Já no tocante as espécies tóxicas, os alunos não relataram inicialmente conhecimento sobre a toxidez, mas mencionaram sobre elas alguma utilização que não incluiu a ingestão do vegetal, muitas destas abrangendo crenças populares e/ou religiosas. Esta interface entre o científico e o conhecimento tradicional, entre o uso medicinal e o uso a partir das crenças, constitui-se num terreno rico para a valorização dos conhecimentos tradicionais.

O uso da planta alecrim (Rosmarinus officinalis L. - Lamiaceae), por exemplo, foi referido pelos alunos para problemas circulatórios e do sistema nervoso. Dados da ANVISA (2014) remetem o uso desta planta para a primeira finalidade, vindo ao encontro dos conhecimentos prévios demonstrados. De forma semelhante, o uso das demais plantas medicinais sempre apresentou pelo menos uma relação com as indicações da literatura. Destacaram-se o uso da camomila (Matricaria recutita L. - Asteraceae) como calmante, da hortelã (Mentha sp. - Lamiaceae) para problemas respiratórios, da malva (Malva parviflora L. - Malvaceae) para inflamações, do sabugueiro (Sambucus nigra L. - Adoxaceae) para gripes/resfriados, e da unha-de-gato (Uncaria tomentosa Willd. ex Schult. - Rubiaceae) para reumatismo. A Tabela 1 apresenta os comparativos entre as informações dos educandos e das referências bibliográficas.

No que se refere às plantas tóxicas, os educandos não relataram informações sobre a toxidez (Tabela 1), mas, curiosamente, relataram apenas usos externos ou não relataram o uso. Por exemplo, para a mamona (Ricinus communis L. Euphorbiaceae) não foi mencionada a utilização, apenas o conhecimento da existência do óleo de mamona. Para a arruda (Ruta graveolens L. - Rutaceae) foi mencionado o uso nas crenças populares, para evitar o "mau-olhado"; da mesma forma para o comigo-ninguém-pode (Dieffenbachia sp. - Araceae), utilizado para banhos de descarrego e para inibir a inveja.

Conforme refere Costa (2008), ao trabalhar com a temática plantas medicinais na escola, é importante estabelecer a associação entre os diferentes saberes que fazem parte deste conteúdo, pois acredita-se que é pelo diálogo entre as diferentes formas de conhecimento que se pode chegar a uma aprendizagem significativa sobre o tema. Por outro lado, com isto, não se afirma que o conhecimento científico deva ser substituto do conhecimento etnocientífico e vice-versa, mas que é importante utilizar desse conhecimento (popular) como uma ferramenta de mobilização cognitiva e afetiva do aluno para a percepção do novo conhecimento que se lhe apresenta: o científico.

Os grupos sociais utilizam plantas a partir de conhecimentos que misturam ciência, arte e magia. As plantas perpassam gerações e transcendem etnias, raças e classes sociais, constituindo-se, portanto, em um recurso autêntico do saber popular, tradicionalmente utilizado no seio familiar e socializado nas relações de vizinhança (Figueiredo, 2005). 
Tabela 1 - Relação de plantas com propriedades medicinais e plantas tóxicas mencionadas pelos alunos da educação de jovens e adultos (EJA).

\begin{tabular}{|c|c|c|c|}
\hline \multicolumn{4}{|c|}{ Plantas com Propriedades Medicinais } \\
\hline Nome Comum & Nome Científico & $\begin{array}{l}\text { Indicação dos } \\
\text { estudantes }\end{array}$ & Informação da Literatura \\
\hline Alecrim & $\begin{array}{l}\text { Rosmarinus officinalis } \mathrm{L} \text {. } \\
\text { (Lamiaceae) }\end{array}$ & $\begin{array}{l}\text { Indicado para } \\
\text { circulação e } \\
\text { problemas do } \\
\text { sistema nervoso. }\end{array}$ & $\begin{array}{l}\text { Indicado para distúrbios circulatórios, } \\
\text { também ação antisséptica e cicatrizante } \\
\text { (Oliveira \& Veiga, 2019). }\end{array}$ \\
\hline Camomila & $\begin{array}{c}\text { Matricaria recutita } \mathrm{L} \text {. } \\
\text { (Asteraceae) }\end{array}$ & $\begin{array}{l}\text { Indicado como } \\
\text { calmante. }\end{array}$ & $\begin{array}{l}\text { Uso para cólicas intestinais, também } \\
\text { como calmante e para ansiedade leve } \\
\text { (Alonso, 2004). }\end{array}$ \\
\hline Hortelã & $\begin{array}{l}\text { Mentha sp. } \\
\text { (Lamiaceae) }\end{array}$ & $\begin{array}{l}\text { Gripe, resfriado, } \\
\text { problemas } \\
\text { respiratórios. }\end{array}$ & $\begin{array}{l}\text { Indicada para o tratamento de } \\
\text { pneumonia, também para } \\
\text { congestionamento e alívio da tosse e } \\
\text { dor de garganta (Albuquerque, 2005). }\end{array}$ \\
\hline Malva & $\begin{array}{l}\text { Malva parviflora } \mathrm{L} . \\
\text { (Malvaceae) }\end{array}$ & $\begin{array}{l}\text { Febre, } \\
\text { inflamações. }\end{array}$ & 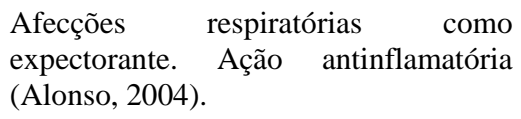 \\
\hline Sabugueiro & $\begin{array}{l}\text { Sambucus nigra } \mathrm{L} . \\
\text { (Adoxaceae) }\end{array}$ & Gripe & $\begin{array}{l}\text { Indicado como diaforético (Anvisa, } \\
\text { 2014), o que muitas vezes é alvo de } \\
\text { busca em tratamentos para gripe. }\end{array}$ \\
\hline Unha-de-Gato & $\begin{array}{c}\text { Uncaria tomentosa } \\
\text { (Willd. ex Schult.) DC. } \\
\text { (Rubiaceae) }\end{array}$ & $\begin{array}{l}\text { Reumatismo, } \\
\text { inflamações } \\
\text { articulatórias. }\end{array}$ & $\begin{array}{l}\text { Inflamações, cistite, úlcera, asma, etc. } \\
\text { (Batiha et al., 2020). }\end{array}$ \\
\hline \multicolumn{4}{|c|}{ Plantas Tóxicas } \\
\hline Nome Comum & Nome Científico & $\begin{array}{l}\text { Indicação dos } \\
\text { Estudantes }\end{array}$ & Informações da Literatura \\
\hline Arruda & $\begin{array}{l}\text { Ruta graveolens L. } \\
\qquad \text { (Rutaceae) }\end{array}$ & Mau olhado & $\begin{array}{l}\text { A planta apresenta potencial terapêutico } \\
\text { também possui toxidade aguda, } \\
\text { incluindo efeito embriotóxico e } \\
\text { teratogênico (Rodrigues et al., 2011). }\end{array}$ \\
\hline $\begin{array}{l}\text { Comigo- } \\
\text { Ninguém-Pode }\end{array}$ & $\begin{array}{l}\text { Dieffenbachia sp. } \\
\text { (Araceae) }\end{array}$ & $\begin{array}{l}\text { Banho de } \\
\text { descarrego, } \\
\text { inveja. }\end{array}$ & $\begin{array}{l}\text { Altamente tóxica, provoca edema na } \\
\text { garganta levando à asfixia e, em casos } \\
\text { extremos, até a morte (Mendieta et al., } \\
\text { 2014). }\end{array}$ \\
\hline Mamona & $\begin{array}{l}\text { Ricinus communis L. } \\
\text { (Euphorbiaceae) }\end{array}$ & Óleo de mamona. & $\begin{array}{l}\text { Embora possua potencial terapêutico, } \\
\text { provoca distúrbios gastrointestinais, } \\
\text { respiratórios e hematológicos } \\
\text { (Sisenando \& Oliveira, 2017). }\end{array}$ \\
\hline
\end{tabular}

Fonte: Autores.

Durante a realização das atividades, evidenciou-se o entusiasmo demonstrado pelos educandos em relação à participação. Foi possível perceber que parte deste entusiasmo teve relação com o tema abordado, mas, principalmente, com o sentimento de valorização dos saberes existentes e pela possibilidade de cada participante contribuir no acréscimo às discussões. Também restou evidente o sentimento de valorização ao perceber que os conhecimentos populares existentes estavam em acordo com as citações científicas sobre as espécies. Kovalski e Obara (2013) ressaltam que este tipo de trabalho coloca em evidência a importância relacionar os conhecimentos discutidos em sala com os saberes do cotidiano, pois fazem 
parte da vida e da cultura dos seus alunos e, assim, facilitam a construção de uma leitura mais crítica sobre a realidade e da relação à grande diversidade de saberes existentes. Os desafios de educar e aprender, assim como formar cidadãos críticos, éticos e protagonistas em seus espaços estão entre os princípios articuladores para a igualdade de oportunidades. Promover um espaço de reflexão individual e coletiva pode contribuir para fortalecer a diversidade dos saberes e contribuir com a construção da cidadania (Lima \& Silva, 2019).

\section{Considerações Finais}

O uso de plantas medicinais constitui-se em uma importante prática sociocultural das populações, sendo fundamental sua valorização como forma de resgatar e fortalecer estes saberes. Não obstante, devem ser realizados esforços para contribuir na elaboração de conhecimentos sobre o uso de plantas com potenciais medicinais e o cuidado com plantas potencialmente tóxicas. Os estudantes da EJA caracterizam-se pela trajetória de vivências, cultura e saberes que trazem consigo para a sala de aula, dentre os quais o conhecimento sobre o uso de plantas. O resgate desse conhecimento representa não apenas a valorização dos saberes tradicionais, como também uma estratégia de valorização dos conhecimentos prévios, estimulando a autoestima e a percepção própria dos estudantes enquanto sujeitos possuidores de conhecimentos.

Foi possível observar que os educandos possuíam, entre si, saberes similares sobre as plantas, os quais mostraram colinearidade aos conhecimentos científicos existentes. No tocante às plantas medicinais, sempre houve relações entre os saberes prévios e as informações obtidas em fontes cientificas e/ou oficiais, enquanto em relação às plantas tóxicas, as aplicações estiveram ligadas especialmente às crenças pessoais dos participantes, mas permitindo evidenciar que não eram ingeridas, também demonstrando relação entre os conhecimentos.

Os estudantes demonstraram entusiasmo ao socializarem seus conhecimentos com os colegas. Especialmente, foi possível perceber que se sentiram valorizados quando observaram que seus conhecimentos possuíam relação com as informações científicas, contribuindo para o processo emancipatório e do reconhecimento próprio enquanto sujeitos detentores de saberes oriundos de suas vivências pessoais.

Por fim, sugere-se que os planejamentos de atividades para a Educação de Jovens e Adultos incluam a valorização de conhecimentos tradicionais, especialmente sobre a flora, como forma de valorizar as trajetórias pessoais de construção de conhecimentos. Não obstante, para estudos futuros, acredita-se que novas abordagens sobre plantas medicinais e tóxicas em contextos diferentes da EJA possam contribuir com a percepção dos diferentes aspectos culturais e com a ampliação do reconhecimento e resgate de conhecimentos tradicionais.

\section{Referências}

Anvisa - Agência Nacional de Vigilância Sanitária. (2014). Formulário de fitoterápicos da farmacopeia brasileira. Anvisa.

Bardin, L. (2009). Análise de Conteúdo. Edições 70.

Batiha, G. E., Beshbishy, A. M., Wasef, L., Elewa, Y. H. A., Abd El-Hack, M. E., Taha, A. E., Al-Sagheer, A. A., Devkota, H. P., \& Tufarelli V. (2020). Uncaria tomentosa (Willd. ex Schult), a review on Chemical constituents and biological activities. Applied Sciences, 10(8), 1-12.

Brasil. Ministério da Saúde. (2006). Política Nacional de Práticas Integrativas e Complementares no SUS - PNPIC - SUS.

Cavaglier, M. C. S., \& Messeder, J. C. (2014). Plantas medicinais no ensino de química e biologia: propostas interdisciplinares na educação de jovens e adultos. Revista Brasileira de Pesquisa em Educação em Ciências, 14(1), 55-71.

Costa, R. G. A. (2008). Os saberes populares da etnociência no ensino das ciências naturais: uma proposta didática para aprendizagem significativa. Didática sistêmica, 8(1), 162-172.

Dávila, E. S., Alves, C. C., Lima, B. M., Folmer, V., \& Puntel, R. L. (2016). Ideias prévias sobre plantas medicinais e tóxicas de estudantes do ensino fundamental da região da fronteira oeste do Rio Grande do Sul. Conexões culturais - revista de linguagens, artes e estudos em cultura, 2(1), $358-386$.

Fernandes, L. R. R. M., Fraga, S. A. P. M., \& Costa, V. B. (2018). Os saberes tradicionais e locais e as indicações geográficas: o caso das plantas medicinais no Brasil. In: Santos, M. G., \& Quintero, M. (Org.). Saberes tradicionais e locais: reflexões etnobiológicas. Eduerj. 
Research, Society and Development, v. 10, n. 6, e5910615569, 2021

(CC BY 4.0) | ISSN 2525-3409 | DOI: http://dx.doi.org/10.33448/rsd-v10i6.15569

Figueiredo, N. M. A. (2005). Ensinando o cuidar em saúde pública. Yendis.

Gadotti, M., \& José, E. R. (2007). Educação de jovens e adultos: teoria, prática e proposta. Cortez.

Kovalski, M. L., \& Obara, A. T. (2013). O estudo da etnobotânica das plantas medicinais na escola. Ciência e Educação, 19(4), 911-927.

Krupek, R. A., \& Nedopetalski, P. F. (2020). O uso de plantas medicinais pela população de União da Vitória - PR: o saber popular confrontado pelo conhecimento científico. Arquivos do Mundi, 24(1), 50-67.

LDB 9394 - Lei das Diretrizes e Bases da Educação Nacional. (1996). Presidência da República. http://www.planalto.gov.br/ccivil_03/leis/19394.htm

Lima, F. R., \& Silva, J. (2019). Saberes pedagógicos no reconhecimento e valorização dos letramentos sociais na Educação de Jovens e Adultos (EJA): revisitando a formação continuada e a prática docente. Revista Brasileira de Educação e Cultura, 1(20), 33-53.

Mello, P. E. D. (2019). Políticas públicas para a produção de materiais didáticos para a educação de jovens e adultos no Brasil entre 1995 e 2017: avanços, contradições, recuos. In: Paiva, J. (Org.). Aprendizados ao longo da vida: sujeitos, políticas e processos educativos. Eduerj.

Mendieta, M. C., Souza, A. D. Z., Ceoloin, S., Vargas, N. R. C., Ceolin, T., \& Heck, R. M. (2014). Toxic plants: importance of knowledge for realization of health education. Journal of nursing, 8(3), 680-686.

Moreno, G. S., \& Silva, G. (2017). Conhecimentos tradicionais em torno das plantas medicinais e currículo do ensino de ciências. Revista Brasileira de Educação no Campo, 2(1), 144-162.

Morin, E. (2013). Os sete saberes necessários à educação do futuro. Cortez.

Oler, J. R. L., Amorozo, M. C. M., Monteiro, R., \& Butturi-Gomes, D. (2019). Etnobotânica de plantas tóxicas como subsídio para campanhas de prevenção de acidentes: um estudo de caso em Cananéia, São Paulo, Brasil. Scientia Plena, 15(11), 1-15.

Oliveira, I. A. (2004). Princípios Pedagógicos na Educação de Jovens e Adultos. http://www.cereja.org.br/pdf/20041116_Ivanilde.pdf.

Oliveira, J. C. A., \& Veiga, R. S. (2019). Impacto do uso do alecrim (Rosmarinus officinalis L.) para a saúde humana. Brazilian Journal of Natural Sciences, $1(2), 1-7$.

Rocha, C. C., \& Vieira, M. C. (2020). O que dizem professores/as da Educação de Jovens e Adultos sobre a interdisciplinaridade: dificuldades e possibilidades de uma práxis transformadora. Imagens da Educação, 10(2), 33-47.

Rodrigues, H. G., Meireles, C. G., Lima, J. T. S., Toledo, G. P., Cardoso, J. L. \& Gomes, S. L. (2011). Efeito embriotóxico, teratogênico e abortivo de plantas medicinais. Revista Brasileira de Plantas Medicinais, 13(3), 359-366.

Santos, B. S. (2004). O Fórum Social Mundial: manual de uso. http://www.boaventuradesousasantos.pt/documentos/fsm.pdf

Santos, B. S. (2010). A gramática do tempo: para uma nova cultura política. Cortez.

Santos, M. G., \& Carvalho, A. C. B. (2018). Plantas medicinais: saberes tradicionais e o sistema de saúde. In: Santos, M. G. \& Quintero, M. (Org.). Saberes tradicionais e locais: reflexões etnobiológicas. Eduerj.

Sisenando, H. A., \& Oliveria, M. F. (2017). Plantas tóxicas: um risco quase invisível à saúde infantil. Uniciências, 21(2), 115-119.

Sinintox - Sistema Nacional de Informações Tóxico-Farmacológicas. (2021). https://sinitox.icict.fiocruz.br/dados-nacionais

Tomazzoni, M. I., Negrelle, R. R. B., \& Centa, M. L. (2006). Fitoterapia popular: a busca instrumental enquanto prática terapêutica. Texto contexto enfermagem, 15(1), 115-121. 